\title{
Mapping stakeholders of the Palestinian Health Research System: a qualitative study
}

Mohammed AlKhaldi, ${ }^{1,2,5,11}$ Abdulsalam Alkaiyat, ${ }^{1,2,5}$ Constanze Pfeiffer, ${ }^{1,2}$ Saleem Haj-Yahia, $,{ }^{4,5}, \mathrm{Ham}^{1}$ a Meghari, ${ }^{7}$ Hassan Abu Obaid, ${ }^{8}$ Ali Shaar, ${ }^{9}$ Yousef Aljeesh, ${ }^{10}$ Marcel Tanner ${ }^{1,2}$ and Yehia Abed ${ }^{3}$

${ }^{1}$ Swiss Tropical and Public Health Institute, Basel, Switzerland. ${ }^{2}$ University of Basel, Basel, Switzerland. ${ }^{3} \mathrm{Al}-$ Quds University, School of Public Health, Jerusalem, Palestine. ${ }^{4}$ The University of Glasgow, Cardiovascular Institute, Glasgow, United Kingdom. ${ }^{5}$ Najah National University, Faculty of Medicine and Health Sciences, Nablus, Palestine. ${ }^{6}$ Bristol University, School of Clinical Sciences, Bristol, United Kingdom. 7 University College London, London, United Kingdom. ${ }^{8}$ Ministry of Health, Gaza, Palestine. ${ }^{9}$ United Nations Population Fund, Jerusalem, Palestine. ${ }^{10}$ The Islamic University of Gaza, Gaza, Palestine. ${ }^{11}$ Council on Health Research for Development (COHRED), Geneva, Switzerland. (Correspondence to: Mohammed AlKhaldi: moh.alkhaldi@ swisstph.ch).

\begin{abstract}
Background: There is a growing international and regional interest in Health Research Systems (HRSs) in light of a global strategy for HRS stakeholders' (HRSSHs) active involvement. HRSSHs in Palestine have rarely been investigated with regard to uncertainties.

Aims: This study aimed to analyse perceptions of HRSSHs in order to understand their roles and involvement, identify gaps, and offer policy solutions for stakeholders' engagement in the Palestinian HRS.

Methods: This qualitative study targeted three local Palestinian health sectors, government, academia, and local and international agencies. Data were collected through 52 in-depth interviews (IDIs) and 6 focus group discussions (FGDs) and then analysed using MAXQDA 12 software. Participants and institutions were selected purposively based on a set of criteria and peer review.

Results: The overall HRS stakeholders' roles were unsatisfactory, with low involvement from society, the private sector, local and international sectors. The role of academia and the Ministry of Health is vital but observed moderate in health research while that of international agencies is weak due to conflicting agendas and lack of a guiding body. Most universities have poor representation in public decision-making and scarcity in health research potential and capacity. Interest-power imbalance among stakeholders is reported where political, organizational, and technical shortfalls were indicative of weak roles and low involvement, along with a lack of health research culture, structure, resources, defined roles, and network.

Conclusions: Tackling the inadequate roles, interests' disparity, and poor involvement of HRSSHs is imperative for HRS strengthening. Redefining HRSSHs' roles and involving all stakeholders is key through strategic dialogue, consolidated leadership, and resource mobilization.

Keywords: Health experts, health research system, stakeholders, Palestine

Citation: AlKhaldi M; Alkaiyat A; Pfeiffer C; Haj-Yahia S; Meghari H; Abu Obaid H et al. Mapping stakeholders of the Palestinian Health Research System: a qualitative study. East Mediterr Health J. 2020;26(3):340-348. https://doi.org/10.26719/emhj.19.016

Received: 05/08/18; accepted: 30/10/18

Copyright (c) World Health Organization (WHO) 2020. Open Access. Some rights reserved. This work is available under the CC BY-NC-SA 3.0 IGO license (https://creativecommons.org/licenses/by-nc-sa/3.o/igo).
\end{abstract}

\section{Introduction}

Health Research System (HRS) is a system encompassing people, institutions and activities to generate high-quality knowledge to be utilized in health improvement (1). HRS involves not only the health sector but also key sectors such as science, education, economy, technology or development systems, or indeed aspects of international or private research systems (2). Stakeholders are a key pillar of the HRS who gain in terms of research regulation, production and utilization. This pillar is interconnected and indispensable for any successful HRS, and it is essential to tackle it in system analysis and mapping. Therefore, the World Health Organization (WHO) definition of HRS has delineated two levels of stakeholders - people and institutions (1). Such people are officially engaged in health research (HR) across different institutions of the Palestinian healthcare system. Their primary task is to boost the capacity and productivity of the HRS to be utilised in health decision-making (3).

HRS is a complex issue with diverse actors and contexts (4) and the lack of common understanding is rooted in its multi-disciplinary nature. Since it has impacts on, and relationships with other key systems, a holistic building and analysis approach is required to fulfill the system's potential in order to attain health and comprehensive development (5). HRS stakeholders (HRSSHs) are the dynamic engine of all HR operations; consequently, grasping their roles, relationships and level of involvement is essential. They can affect or be affected by the HRS and are considered an important source of information and critical perspectives (2).

For system understanding and strengthening, different conceptual HRS frameworks that identified HRS boundaries were used $(6,7)$. In addition, a wide- 
range analysis approach was employed using a stakeholder analysis technique (8) to map HRSSHs. This useful combination technique was adopted to identify stakeholders' influence and importance that may significantly impact HRS success $(2,9)$. The technique was also applied to examine stakeholders' engagement across the HR process, from setting up priorities to disseminating results (10). The advantage of HRSSHs' involvement increases the utilization of HR to support the healthcare system's performance and subsequently promote population health (11,12). By contrast, stakeholders' disengagement creates gaps in the formulation of HR policies and priorities (12).

Even though the support of international HRSSHs, particularly donors' support, is indispensable and needs to be used effectively to build proper research institutions (13), their contribution is often inadequate and conflicting (14). For example, one concern that should be addressed in Palestine as a main aid recipient country is the negative influence of donors on the local research and policy agenda $(15,16)$. Therefore, understanding the role of international HRSSHs as aid suppliers is important to ensure effective use of their contribution to strengthen the HRS in Palestine.

As a central pillar of HRS, this study addresses the HRSSHs issue as the first national study in Palestine and the region (17). The study is the fourth study of a larger research project that investigated all HRS components, which is a necessity not only for the healthcare system but also for Palestine in general as an emerging state. The overall aim is to understand the roles and contributions of HRSSHs in order to bridge the knowledge gap and provide demonstrable strengthening insights to decision-makers. Four objectives were formulated to achieve this aim:

1. Explore the roles, functions and responsibilities of local HRSSHs in the Palestinian HR arena.

2. Assess the role of international agencies and institutions with regard to HR support and contributions.

3. Map the level of involvement and influence of national and international HRSSHs.

4. Determine weaknesses and propose improvements to promote active involvement of HRSSHs.

\section{Methods}

This qualitative study used a similar design to other local studies relying on different system analysis frameworks developed by Pang et al. $(2,3)$ framework, system thinking, and comprehensive HRS assessment. The same tools were used and included a set of dedicated questions on HRSSHs. The study targeted a diverse group of stakeholders including experts, policy-makers, academics, and directors from the three relevant Palestinian sectors: government, academia, and local and international non-governmental organizations (NGOs). The methods of data collection, management and analysis were similar to other national studies $(18,19)$. Data were collected through 52 in-depth interviews (IDIs) and 6 focus group discussions (FGDs) and then analysed using MAXQDA 12 software (VERBI GmbH, Berlin, Germany). Participants and institutions were selected purposively based on a set of criteria and peer review.

In order to obtain a precise realization of HRSSHs involved in HR in Palestine and map appropriately their roles and influence, the study approached the participatory stakeholders' analysis through three methods relying on experts' perspectives, the principal investigator's knowledge, and pertinent literature. The analysis was completed through the three approaches of analysis: the conceptual context of experts (participants' perceptions), the HRSSHs involvement-roles continuum, and the HRSSHs power-interest grid.

\section{Ethics clearances}

The Research Commission of Swiss TPH approved the study (FK No. 122; approval date: 21 October 2015). Ethical approval was also obtained from Ethikkommission Nordwest und Zentralschweiz (EKNZ) in Switzerland (reference No. UBE-15/116; approval date: 23 January 2016). Ethical and administrative approval was received from the Palestinian Ministry of Health (approval date: 28 April 2016); the institutional review board of Helsinki Committee in Palestine (reference No. PHRC/HC/73/15; approval date: 7 December 2015); and the institutional review board (IRB) at Najah National University (NNU) (reference No. 112/Nov./2015 (approval date: 6 December 2015).

\section{Results}

The findings cover two domains: 1) socio-demographic characteristics of study participants; and 2) the overall status of local and international HRSSHs.

\section{Socio-demographic characteristics of study participants}

This aspect was clearly illustrated elsewhere in the literature, which addressed other HRS topics in Palestine $(18,19)$. Overall, the study participants had diverse backgrounds and leadership positions. The majority were educated to doctoral level and held more than 20 years of experience, particularly those participants from NGOs. One third of the participants were female. Participants and their institutions were distributed as follows: $18 \mathrm{ex}$ perts from 8 academic institutions, 19 participants from 15 NGOs (10 local and 5 international), and 15 participants from governmental institutions.

\section{The status of HRSSHs}

There were four aspects related to HRSSHs: 1) the role and responsibilities of HRSSHs; 2) their level of involvement; 3) power/interest factor; and 4) the role of international actors in HR.

\section{The role and responsibilities of HRSSHs}

As indicated in Table 1, the findings on the role of the HRSSHs were combined where national stakeholders' roles were not appreciated by the majority of experts. Most of the responses were distributed into two catego- 
ries: negative perceptions and positive perceptions. Responses to the first category were the most frequent and reflected a conservative and unfavorable perception of the role of HRSSHs and reflected by a diverse spectrum of remarks, such as: "non-robust and weak", "fragmented and seasonal", "unsatisfactory and inadequate", "unfulfilled", "competitive and non-integrative", and few echoed, "there are no stakeholders". In contrast, the positive and more specific category was less frequent. Responses included: "somewhat cooperative", "impressive at the micro-institutional level", "a pivotal and good academic role while weak at the governmental level", and "all roles are improving and can be better". Three specific quotes reflected this, with a government expert stating: "All HRSSHs are working independently"; an academic added: "weak role due to the producer-user gap where HR production is personal"; while an NGO expert echoed "each party does its best but the overall role is not as wished".

In a relevant context, a number of experts agreed principally on the importance of the binary-role of the Ministry of Health $(\mathrm{MoH})$ and academia in HR. Experts emphasized the unilateral regulatory and governing role of the $\mathrm{MoH}$ through the Palestinian National Institute of Public Health (PNIPH), and to remain a major reference, funder and user of HR. However, some NGOs experts in focus group discussions strikingly disagree on the mandate and capacity of the institute with regards to HR. Alongside some academics, they criticized the government's role in managing, funding and directing HR. Although a few praised the role of the Ministry of Higher Education (MoHE) in embedding scientific research in curricula and supporting research initiatives, some described these initiatives as individualistic. The question of who can share the role of $\mathrm{MoH}$ and other government ministries was controversial. Some suggested that academia could take up this role, others referred to WHO, and a few expressed the opinion that all relevant parties need to be involved. Some experts argued that the academic role is limited to HR production only, although two academics criticized the low level of this role. Remarkably, the financing role of both private, local and international NGOs sectors is criticized by a group of experts among the three sectors. An NGO expert echoed that the INGOs are important in the HR scope. In contrast, an expert from the same sector refuted this perception.

\section{The pattern of stakeholders' involvement}

Figure 1 illustrates the involvement level of HRSSHs, which also reinforces many of the aforementioned pertinent perceptions. The continuum figure represents the actors through three dimensions: institutional and societal, individual, and assigned roles. The continuum has a dualistic explanation: 1) depicts the current level of engagement of the HRSSHs according to the demonstrated three dimensions; and 2) indicates that the current representation is a factual reflection of a successful HRS, but on condition that the scaling up of the three dimensions to a higher level is ensured. In other words, tri-involvement, society-institution-individual, needs to be constantly maximized, so that each role becomes representa-

\begin{tabular}{|c|c|}
\hline \multicolumn{2}{|r|}{ HRSSHs role } \\
\hline Government & $\begin{array}{l}\text { - Not strong } \\
\text { - Vital academic role } \\
\text { - Still weak } \\
\text { - A great at the micro-institutional level } \\
\text { - To some extent cooperative role } \\
\text { - Cannot evaluate their disorganized role due to no } \\
\text { system } \\
\text { - All stakeholders are working independently } \\
\text { - Overall role is not satisfying }\end{array}$ \\
\hline Academia & $\begin{array}{l}\text { - Their roles are negatively performed } \\
\text { - Not good due to disorganized and unvalued HR } \\
\text { among care providers } \\
\text { - Competitive roles rely on personal interests } \\
\text { - Insufficient role with unclear tasks } \\
\text { - Limited and need empowerment } \\
\text { - All do not perform their role as required due to } \\
\text { individualism and system gap } \\
\text { - Their roles are dispersed } \\
\text { - Weak roles due to the producer-user gap and } \\
\text { producing HR for personal goals } \\
\text { - There are no stakeholders } \\
\text { - Individual roles and agendas }\end{array}$ \\
\hline NGOs & $\begin{array}{l}\text { - Each party do its best but the overall role is not as } \\
\text { wished } \\
\text { - Disintegrated sectorial work with a shortage in } \\
\text { their assigned roles } \\
\text { - Inadequate where most of their role is just } \\
\text { services provision } \\
\text { - Lacking a good linkage among all with } \\
\text { unsatisfactory roles of gov. and academia } \\
\text { - Vague roles, care provider or HR regulator } \\
\text { - Difficult to evaluate their roles while no structure } \\
\text { or system } \\
\text { - Academia role is good but the government is } \\
\text { inefficient } \\
\text { - Fragmented and seasonal efforts } \\
\text { - All Stakeholders are playing an important role } \\
\text { - They do not work collaboratively } \\
\text { - Their role is improving and can be better } \\
\text { - A competitive role rather than complementary } \\
\text { teamwork } \\
\text { - No, they are not well-performing with a server } \\
\text { performance shortage } \\
\text { - Many attempts but unsatisfactory roles } \\
\text { - Current roles are completely fragmented }\end{array}$ \\
\hline
\end{tabular}

tive and weighted in HRS. Certainly, the first dimension showed government and academia as the most involved parties, while the private sector and community were insufficiently involved. Finally, as experts delineated, most of the assigned roles of the HRSSHs in the continuum are almost identified realistically, with varying levels of government and academic involvement in HR, but both actual roles remain weak.

\section{Mapping HRSSHs in accordance to Power/interest Grid}

Figure 2 displays the distribution grid of HRSSHs in Palestine. This analytical grid aims for a better understanding of the actors' interactions and influence and it comprises four quadrants. Four national bodies, academia, and WHO are almost located in the first quadrant, high power-high interest, where most Palestinian academic institutions are national NGOs. The second quadrant shows high power-low interest, and includes most of 


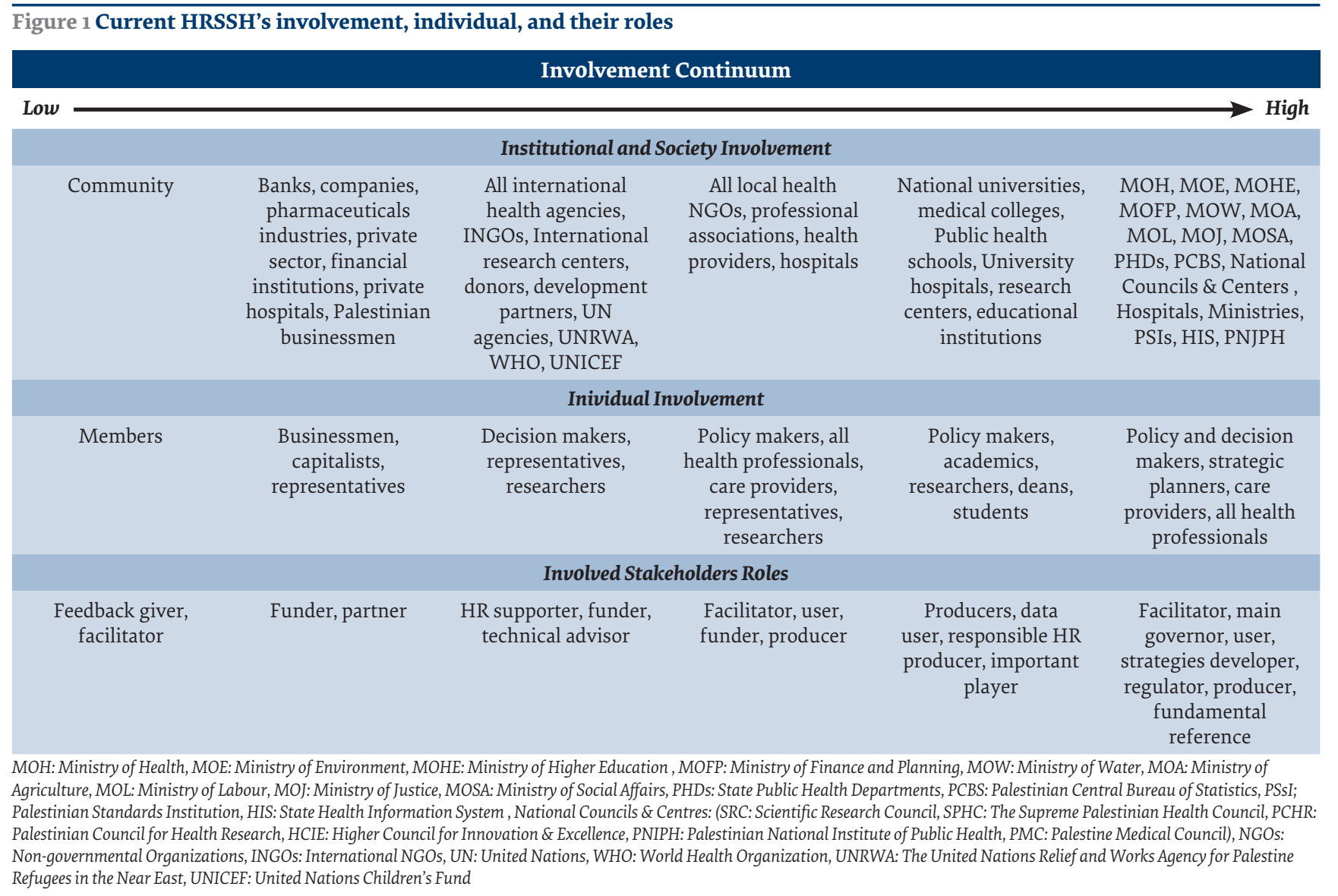

the government ministries and the highest sovereign institutions, headed by the president, Palestinian legislative council (PLC), Cabinet, and MoH. Low power-high interest is the third quadrant, which shows the lowest stakeholders' representation, excluding certain academic institutions and INGOs. The last quadrant is low power-low interest, where few national bodies, most INGOs, local NGOs, the private sector, professional associations, and community are situated. Importantly, the overall reflection is that the majority of national and governmental bodies dominate the power structure, but with a low interest in HR. Unlike international and local NGOs, private and community institutions that have low power, as well as academia and some INGOs who possess moderate power and a prominent interest, contribute best to HR.

\section{The role of international actors in health research in Palestine}

As demonstrated in Table 2, the general perception indicates that the international role in supporting $\mathrm{HR}$ is currently indispensable but ineffective. This is evidently shown in the majority of experts' beliefs that this role is still at a low level; a few experts hailed the financial and technical role, but on an ad-hoc basis with a non-strategic motive and value. A substantial agreement across the three sectors was observed with regards to the factors behind the weakness of this role, which were:

1. Political - fund conditions, donor agendas, and political mandates.

2. Opaque factors influencing donor's roles; unsustain- able, unpredictable and inadequate resources, and essentially low interest to HR.

3. Factors related to their operational role, as mainly emergency-based, humanitarian-oriented and project-driven and with a short-term scope. Donors' activities do not meet local needs, and their selective support for HR is often related to evaluating their own implemented programmes.

Two policymakers delineated "plays a positive role but insufficient and unsystematic in supporting advanced HR"; an academic viewed that, "this role is not efficient and unsustainable, and far from our interest"; while NGOs noted that, "the role is majorly humanitarian-focused".

The findings came with a range of thoughts for solutions to enhance this role. One important solution, which was frequently expressed by experts, is the need to speed up forming a unified national advisory policy entity for $\mathrm{HR}$; a few suggested the PNIPH for this assignment. This body's mission with the involvement of all HRSSHs would be to formulate a national strategy, including a national fund for regulating, prioritizing and funding HR. In light of this strategy, it is important to focus on revitalizing the leadership role of $\mathrm{MoH}$ and/ or PNIPH to allocate and manage the international fund appropriately towards HRS components, primarily investing in human and infrastructure capacity building. Furthermore, a strategic dialogue led by $\mathrm{MoH}$ with local and international donors needs to be 
Government - Supports some HR, clearly, their role does not reach the required level

- No remarkable role and their HR minimally address our needs

- Unclear role and performed according to their agendas

- They fund some scientific events and selective HR with limit involvement depending on their agendas

- Do not know sufficiently about their role, but generally based on initiatives and remains inadequate

- Do not know well but I think they fund HR based on need

- A valued role but focuses only on finance assistance

- Plays a positive role but insufficient in supporting advanced HR such as radiation exposure, oncology, etc

- Plays an important role but in unsystematic approach

- Their role depends on their agenda

- Essential role and indispensable sponsor

- The national HR relies on donors due to no state budget and body

Academia - The majority of actors implement relief projects rather than HR

- Their fund is decreasing, health is not a priority instead of the security sector and projects-based

- Their role seeks to fulfill their agenda, should not be relied on

- Funding their own agenda and HR is not their priority

- A fundamental role but influences HR priorities

- It is not that efficient and sustainable, the role is far from our interests

- Their fund is the main source but the role is questionable

- They play a key role but insufficient

- Conditioned fund according to their goals

- It is supportive concerning the technical assistance

- Funding HR that are related to their projects and serves their ideologies

- It is emergency and relief-oriented

- Relies on donor goals with a lack of attention to HR does not meet our needs

- It is selective and based on projects meeting their priorities

- Supports HR but according to their ideologies

- I do not think that it is important where their goals are political

- Political and does not consistent with the Palestinian population needs

- Mentioning their role makes me nervous where Palestine is out of their priorities

- It is a prominent role

- Actually, do not know but there are some research projects supported externally

- An important role but imposes their agenda where HR is not in their scope

- Has its own agendas

- Most of the donors work on relief and emergencies and support

HR to evaluate their programmes

- Provides the government technical and financial support related to the health system and research

- It has a major role mainly in humanitarian crises

- It neglects to establish HR body without attention from $\mathrm{MOH}$

- I do not think that it has a major role in HR where the huge fund goes to the $\mathrm{MOH}$ operations

- It is the second source works on agendas and directed for relief projects not purely for HR

- Finances HR according to its agenda

It is limited and does not meet the scientific research
Agreed national HR vision and agenda is a priority to gear this role

- Their role is crucial to help institutions in HR utilization and benefiting from their experience

Regular prioritization exercise is crucial

Technical and financial support together are needed Optimal use of resources should be adopted

Urge to promote the role of the influential role and guiding duty

Establish long-term funding with solid commitment based on national HR developmental strategy

A reform HR strategy to improve its operations

Collective national involvement is a demand includes international players in HR planning and implementation relying on national health needs

- A national health institute or council could be the PNIPH, to be a body to manage the international efforts

- A strategic dialogue is required to find a common point gaping the donor agenda and the national priorities

- A need for fund diversification not relying on one source and maximizing the national funding through companies, banks, diaspora Palestinian communities, and associations. Etc.

- Urge the donor's fund to be invested in capacity building programs and resources provision

Partnerships with internal and international players

Promote their role in getting a state political independence

Using it in empowering our human resources

Founding a national supervisory committee to guide this fund appropriately

- This fund needs to be linked with a clear strategic vision reflects the society needs and

- Government leaders should build a collective body and national HR network and need to settle HR and to be guided by other abroad successful experiences

A solid agreed HR vision which must not be changed by all kinds of funding while this funding should serve this vision

- Donors duty is to monitor and evaluate the fund but not to impose agendas

- Palestinian institutions and donors should focus on needs not on finding and irrelevant agendas

Institutional HR units across local and donors need to be established.

launched in order to formulate a common and longterm vision linking their fund structurally with the local HR needs and priorities. Other perceptions emphasized that maximizing and diversifying fund sources for a sustainable funding pledge is indispensable and should be managed by appealing to national institutions, individuals and communities abroad. Furthermore, optimizing the use of resources and prioritizing HR on a regular basis through solid technical and governance procedures. Another reported enhancing factor was 


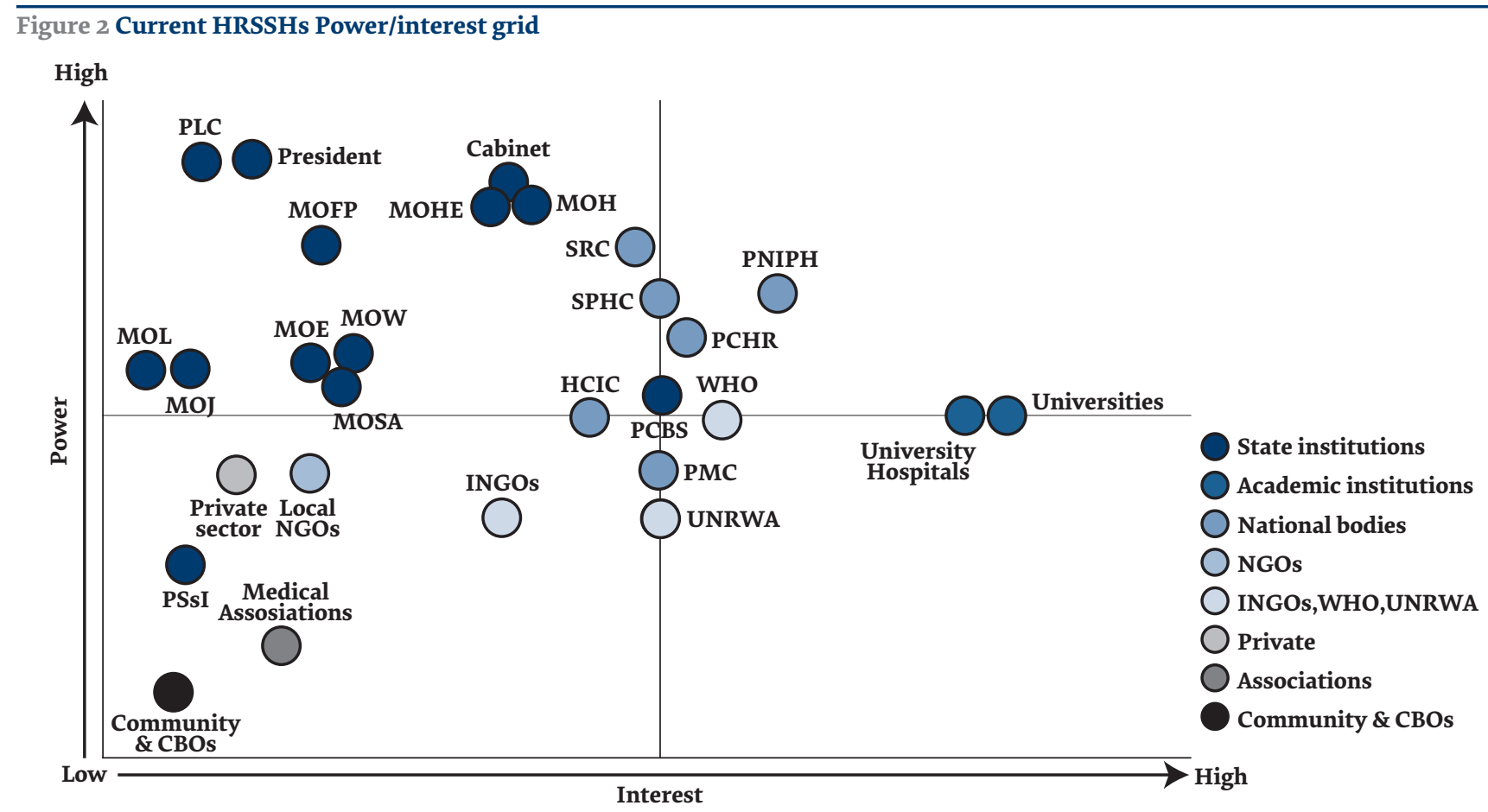

PCL: Palestinian Legislative Council, MOHE: Ministry of Higher Education, MOH: Ministry of Health, MOFP: Ministry of Finance and Planning, MOL: Ministry of Labour, MOJ: Ministry of Justice, MOE: Ministry of Environment, MOW: Ministry of Water, MOSA: Ministry of Social Affairs, PCBS: Palestinian Central Bureau of Statistics, PSsI; Palestinian Standards Institution, SRC: Scientific Research Council, SPHC: The Supreme Palestinian Health Council, PCHR: Palestinian Council for Health Research, HCIE: Higher Council for Innovation \& Excellence, PNIPH: Palestinian National Institute of Public Health, PMC: Palestine Medical Council, NGOs: Non-governmental Organizations, CBOs: Community Basd Organizations, INGOs: International NGOs, WHO: World Health Organization, UNRWA: The United Nations Relief and Works Agency for Palestine Refugees in the Near East

defining the role of the donors in the supervision, monitoring and evaluation of this fund, which should be done under state leadership. Lastly, donors should be urged to establish HR units associated with the national HR body and, more importantly, their technical assistance and fund should be harnessed for establishing sustainable HRS in Palestine.

\section{Discussion}

This study dealt with one of the most important pillars of the HRS (3) - analysing the involved HRSSHs in the Palestinian HR arena. As HRS has a complex and diverse context $(2,4)$ and is under growing attention $(1,5,19)$, the findings of this study can be helpful to Palestinian policy-makers with regard to understanding the pattern and network of stakeholders in order to move forward towards a successful HRS based on active participation.

As a substantial pillar, HRSSHs forms the primary driving force of the HRS; analysing their views gives a better understanding of how to improve their roles and performance (20). The study found that the overall role of the Palestinian HRSSHs is below the required level (21), evidently described as unsatisfactory and scattered. In other words, such roles have been criticised as being severely deficient in terms of HR funding, production and application. Such findings largely intersect with another pertinent study (22) that found fragmented HRSHs roles are assumed to be a leading problem and resulting in system under-performance. The proposed bilateral functional roles, such as the $\mathrm{MoH}$ with academia or other bodies, are not an effective solution under various system contexts. Hence, as the literature suggests $(4,21)$, a participatory, representative and inclusive approach would be more appropriate under an agreed governing framework.

In the Palestinian HR context, the government and academia - whether institutional or individual are clearly involved, but still play an insufficient role, which hinders the strengthening of HR outputs for translation into sound health policy (8). In return, the less involved stakeholders such as private NGOs and the community are likely related to structural system problems. This indicates that all parties have different and sometimes conflicting agendas. These results were notably inconsistent with WHO's HR strategy that calls for sectorial inclusiveness and strategic partnerships among all HRSSHs (23). Likewise, the literature urges for harmony between the system and HRSSHs goals (4) and HRS values and principles (21), as HR agendas are increasingly shaped by players' involvement (2).

In fact, a power-interest interface is a valuable supplementary approach for a better understanding of the actors' interaction in HRS. In this study, it was observed that the government bodies own the power factors with a significant low interest. This may be interpreted as the need to consult and satisfy these bodies carefully to meet their needs. However, actors with a moderate power and a good HR interest, such as academia, PNIPH, and WHO, are required to expand their roles and involvement (24). The overall indication on this issue is the lack of official attention, orientation, and investment in $\mathrm{HR}$, which is consistent with previous studies from Palestine (18) and 
elsewhere (6,25-28). Importantly, the community, private industry, and INGOs, which are inactive when it comes to $\mathrm{HR}$, are also important groups to be involved due to their untapped influence $(1,2,8,21,28,29)$.

Undoubtedly, the donors' role in supporting HRS in fragile settings is crucial as long as it is directed meaningfully to serve crisis management (30). Their role in building proper research institutions is perceived as weak and unclear in Palestine (15,31,32); consequently, donors rarely run $\mathrm{HR}$. Their investment in $\mathrm{HR}$ is selective, driven by external agendas with unsustainable funding (28), and mostly emergency-based projects. Because Palestine faces unstable political, economic and social pressures, this fund should be harnessed jointly and optimally in HR as a vital development pillar to meet long-term national needs. To achieve this, a collective national body, which may be led by the $\mathrm{MoH}$ or another national entity such as PNIPH, should harness this fund and technical aid and usefully align with a national vision (33) supported by a collaboration strategy. The Paris Declaration-Accra Agenda for Action and ESSENCE are initiatives dedicated to donors' efforts alignment on HR. Such international decrees are needed in the Palestinian HRS to improve the coordination and harmonization of research capacity investments $(14,34)$.

\section{Limitations}

Although this study contributes to bridging the knowledge gap, a scarcity of literature and reports was noted. Furthermore, movement restrictions due to political instability and study time constraints were also a limitation to capture more participants and institutions. Eventually, gathering quantitative data on HR stakeholders was hindered by the lack of data availability, quality and accessibility.

\section{Conclusion}

Stakeholders are a central component of the HRS where it forms the functional driving force. Therefore, understanding their roles is a prerequisite for any strengthening effort. The performance of the HRSSHs is generally below the required level, although both academia and $\mathrm{MoH}$ moderately play important roles. Distinctly different from the development and services NGOs, it is worth mentioning that the majority of universities in Palestine are national NGOs, where their poor representation in public decision-making and potential scarcity hinders a growing academic interest in HR. In summary, the weakness of HRSSHs roles and involvement is the result of political, organizational and technical shortfalls. Imbalance in the interest-power pattern among stakeholders is considerably reported. The critical need is to enhance the involvement balance and correcting pattern of a power-interest factor among all stakeholders to get them all involved, interested and influential. All HRSSHs roles should be appropriately redefined and invested at the official level and work synergistically to reach a high power-interest. Undoubtedly, as it is also applied to the capacity components of HRS, establishing a clear strategy with a collective involvement is a serious demand. It is clear that the role of external donors in supporting HR is substantially inadequate given the paucity of domestic resources and instability. This role needs to be strengthened through a long-term plan that reflects the national needs and a comprehensive strategic dialogue among local and international parties is important and desirable.

\section{Acknowledgments}

This study forms part of a complete research project (17) through a cooperation agreement between two partners, Swiss TPH in Switzerland and Najah National University NNU in Palestine. NNU contributed in forming a research team, which supported and assisted in different fieldwork activities. The Swiss Federation through the Swiss Government Excellence Scholarships for Foreign Scholars is also acknowledged for providing the stipend of the principal investigator. Ultimately, special thanks to Dr. Yousef Abu Safia, former Minister of Environment in Palestine, who contributed to the revision of the study manuscript.

Funding: This work is jointly sponsored by the Swiss Federation through the Swiss Government Excellence Scholarships for Foreign Scholars and the Swiss TPH. The second sponsor had a role in the scientific and technical consultation and guidance.

Competing interests: None declared.

\section{Cartographie des parties prenantes du système de recherche en santé palestinien : étude qualitative \\ Résumé}

Contexte : Il existe un intérêt croissant, aux plans régional et international, pour les systèmes de recherche en santé du fait de la stratégie mondiale consistant à impliquer activement les parties prenantes desdits systèmes. Ces dernières ont rarement fait l'objet d'études portant sur leurs incertitudes en Palestine.

Objectifs : La présente étude visait à analyser les perceptions des parties prenantes des systèmes de recherche en santé, afin de comprendre leurs rôles et leur implication, d'identifier les éventuelles lacunes et d'offrir des solutions politiques à leur engagement dans le système de recherche en santé palestinien. 
Méthodes : Cette étude qualitative ciblait trois secteurs locaux de la santé en Palestine, les agences gouvernementales, universitaires, et locales et internationales. Les données ont été recueillies par le biais de 52 entretiens approfondis et de six discussions thématiques de groupe, puis analysées à l'aide du logiciel MAXQDA 12. Les participants et les établissements ont été sélectionnés intentionnellement sur la base d'un ensemble de critères et d'un examen collégial.

Résultats : Globalement, les rôles des parties prenantes du système de recherche en santé n'étaient pas satisfaisants. Ils démontraient en effet un faible degré d'implication de la part de la société, du secteur privé et des secteurs local et international. Le rôle des universités et du ministère de la Santé est vital, mais on observe qu'ils jouent un rôle modéré dans la recherche en santé. Celui des agences internationales est mineur en raison de la divergence de leurs programmes et de l'absence d'organe directeur. La plupart des universités sont mal représentées dans les processus de prise de décision publique et doivent faire face à la pénurie des potentiels et des capacités en matière de la recherche en santé. Un déséquilibre entre intérêt et moyens a été relevé parmi les parties prenantes, avec des déficits politiques, organisationnels et techniques indicatifs de la faiblesse des rôles et de l'implication. On note par ailleurs des insuffisances en termes de culture, de structure, de ressources, de définition des rôles et de réseau relativement à la recherche en santé.

Conclusions : Il est impératif de s'attaquer à l'inadéquation des rôles, à la divergence des intérêts et au faible degré d'implication des parties prenantes des systèmes de recherche en santé si l'on veut renforcer ces systèmes. Pour ce fait, il importe de redéfinir les rôles des parties prenantes et de les impliquer toutes par la voie d'un dialogue stratégique, d'un encadrement renforcé et d'une mobilisation des ressources.

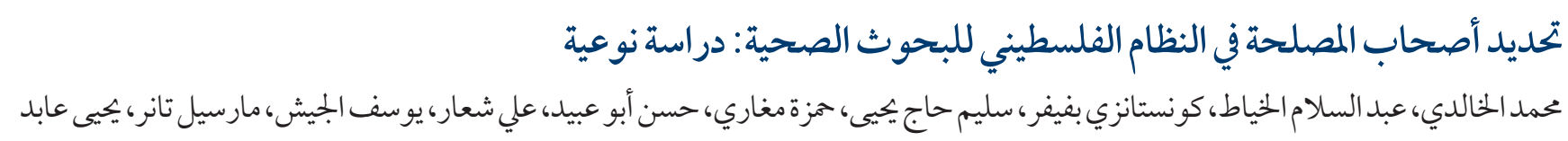

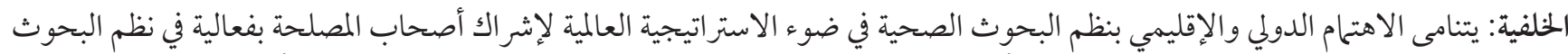

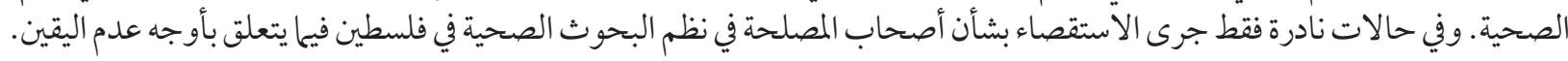

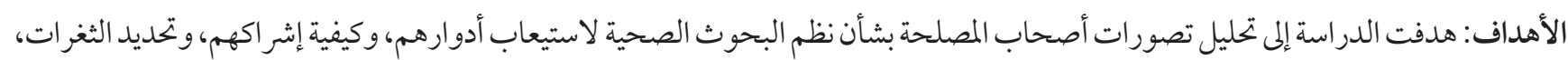

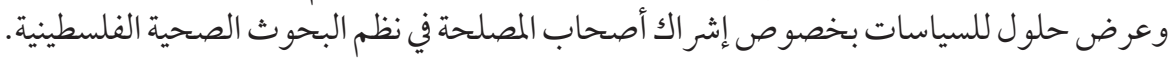

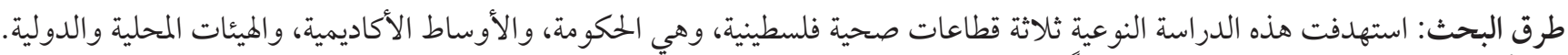

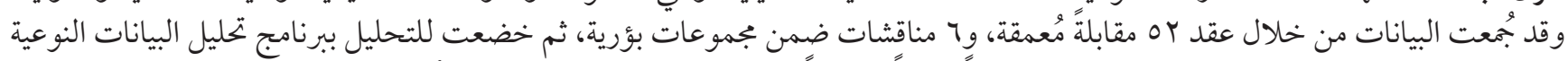

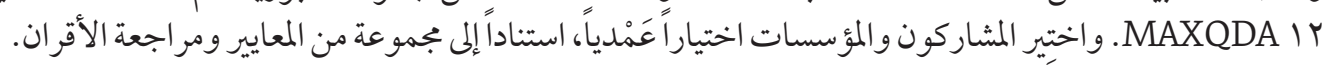

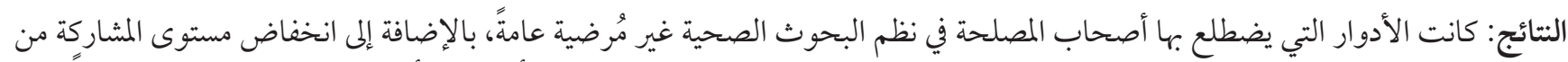

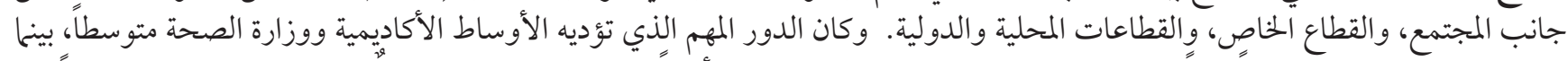

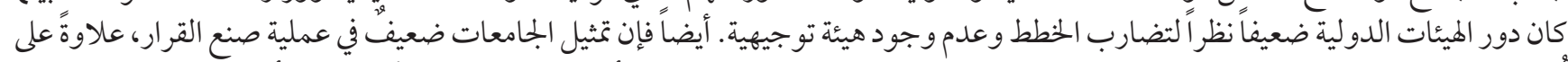

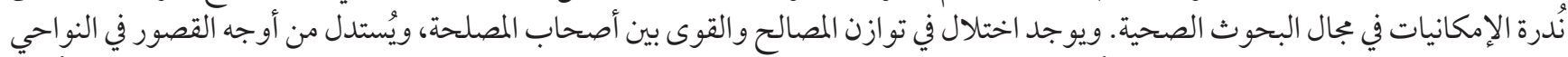

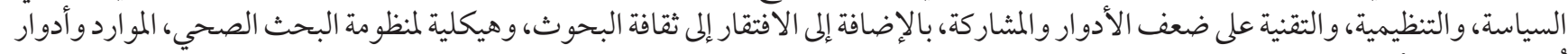
مُحددة لشبكة الأطراف ذات العلاقة.

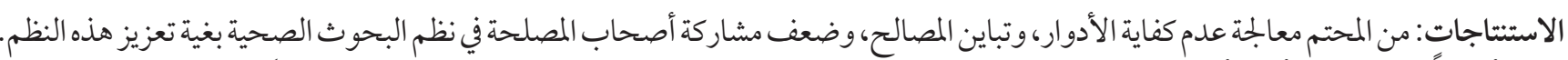

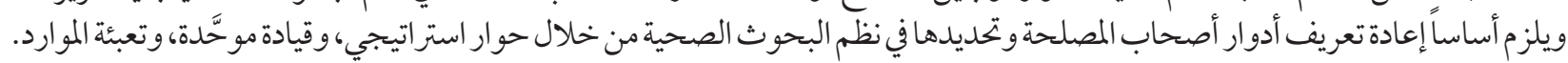

\section{References}

1. Kennedy A, Khoja TA, Abou Zeid AH, Ghannem H, IJsselmuiden C. National health research system mapping in 10 Eastern Mediterranean countries. EMHJ-East Mediterr Health J 143 502-517 2008. 2008.

2. Pang T, Sadana R, Hanney S, Bhutta ZA, Hyder AA, Simon J. Knowledge for better health: a conceptual framework and foundation for health research systems. Bull World Health Organ. 2003;81:815-20.

3. Sadana R, Pang T. Current approaches to national health research systems analysis: a brief overview of the WHO health research system analysis initiative. Cienc Saude Coletiva. 2004;9:351-362.

4. Hanney S, Kuruvilla S, Soper B, Mays N. Who needs what from a national health research system: lessons from reforms to the English Department of Health's R\&D system. Health Res Policy Syst. 2010;8:11.

5. Andrew Kennedy, Carel IJsselmuiden. Building and strengthening national health research systems. A manager's guide to develop- 
ing and managing effective health research systems. 2006. http://www.cohred.org/downloads/cohred_publications/NHRS_Assessment_manual_review_version_FINAL.pdf. Accessed 16 Feb 2018.

6. Ismail SA, McDonald A, Dubois E, Aljohani FG, Coutts AP, Majeed A, et al. Assessing the state of health research in the Eastern Mediterranean Region. J R Soc Med. 2013;106:224-33.

7. Lairumbi GM, Parker M, Fitzpatrick R, Mike EC. Stakeholders understanding of the concept of benefit sharing in health research in Kenya: a qualitative study. BMC Med Ethics. 2011;12:20.

8. Schiller C, Winters M, Hanson HM, Ashe MC. A framework for stakeholder identification in concept mapping and health research: a novel process and its application to older adult mobility and the built environment. BMC Public Health. 2013;13:428.

9. Hyder A, Syed S, Puvanachandra P, Bloom G, Sundaram S, Mahmood S, et al. Stakeholder analysis for health research: Case studies from low- and middle-income countries. Public Health. 2010;124:159-66.

10. Health Knowledge. Identifying and managing internal and external stakeholder interests. 2010. https://www.healthknowledge.org. uk/public-health-textbook/organisation-management/5b-understanding-ofs/managing-internal-external-stakeholders. Accessed 14 Mar 2018.

11. Concannon TW, Fuster M, Saunders T, Patel K, Wong JB, Leslie LK, et al. A systematic review of stakeholder engagement in comparative effectiveness and patient-centered outcomes research. J Gen Intern Med. 2014;29:1692-1701.

12. Fadi El-Jardali, Jihad Makhoul, Diana Jamal, Michael Kent Ranson, Nabil M Kronfol, Victoria Tchaghchagian. Eliciting policymakers' and stakeholders' opinions to help shape health system research priorities in the Middle East and North Africa region. Health Policy and Planning. 2010;25:15-27.

13. Jacobs M, Haan S de. Health research systems: an evolving framework. Bull World Health Organ. 2003;81:624-624.

14. WHO. Seven principles for strengthening research capacity in low- and middle-income countries: simple ideas in a complex world. 2014. http://www.who.int/tdr/publications/Essence_report2014_OK.pdf?ua=1. Accessed 16 Feb 2018.

15. Lee K, Mills A. Strengthening governance for global health research. BMJ. 2000;321:775-6.

16. IJsselmuiden C, Jacobs M. Health research for development: making health research work ... for everyone. Scand J Public Health. 2005;33:329-33.

17. AlKhaldi M. Palestinian Health Research System: Moving Forward. Ph.D. Thesis. University_of_Basel; 2018.

18. AlKhaldi M, Abed Y, Pfeiffer C, Haj-Yahia S, Alkaiyat A, Tanner M. Assessing policy-makers', academics' and experts' satisfaction with the performance of the Palestinian health research system: a qualitative study. Health Res Policy Syst. 2018;16. doi:10.1186/ s12961-018-0341-x.

19. AlKhaldi M, Abed Y, Pfeiffer C, Haj-Yahia S, Alkaiyat A, Tanner M. Understanding the concept and importance of the health research system in Palestine: a qualitative study. Health Res Policy Syst. 2018;16. doi:10.1186/s12961-018-0315-Z.

20. National Health Research Systems: report of an international workshop. Geneva: World Health Organization; 2001.

21. The WHO strategy on research for health. Geneve (Suisse): OMS, World Health Organization; 2012.

22. AlKhaldi M, Alkaiyat A, Abed Y, Pfeiffer C, Halaseh R, Salah R, et al. The Palestinian health research system: who orchestrates the system, how and based on what? A qualitative assessment. Health Res Policy Syst. 2018;16. doi:10.1186/s12961-018-0347-4.

23. Sweileh WM, Zyoud SH, Al-Khalil S, Al-Jabi SW, Sawalha AF. Assessing the scientific research productivity of the Palestinian higher education institutions: A case study at An-Najah National University, Palestine. SAGE Open. 2014;4:2158244014544287.

24. Ayman Haj Daoud, Abdel Rahim Abu Saleh, Imad Khatib, Osama Mimi, Irene Akra, Salwa Zahran. Scientific Research in Palestine. Research. Palestine: Palestine Academy for Science and Technology; 2002. http://www.palestineacademy.org/main/images/stories/ Pdf/Publications/Survey\%20of\%2oResearch\%20in\%20Palestine\%20English.pdf. Accessed 16 Feb 2018.

25. D'Souza C, Sadana R. Why do case studies on national health research systems matter? Identifying common challenges in low- and middle-income countries. Soc Sci Med. 2006;62:2072-8.

26. Mahmoud Fathalla. A Practical Guide for Health Researchers. 2004. http://www.who.int/ethics/review-committee/emro_ethics_ dsa237.pdf. Accessed 25 May 2018.

27. COHRED. Visibility of Arab countries in the world biomedical literature. Libyan J Med. 2011;6:6325.

28. Gonzalez Block MA, Mills A. Assessing capacity for health policy and systems research in low and middle-income countries*. Health Res Policy Syst. 2003;1:1.

29. Woodward A, Sondorp E, Witter S, Martineau T. Health systems research in fragile and conflict-affected states: a research agenda-setting exercise. Health Res Policy Syst. 2016;14:51.

30. El-Jardali F, Adam T, Ataya N, Jamal D, Jaafar M. Constraints to applying systems thinking concepts in health systems: A regional perspective from surveying stakeholders in Eastern Mediterranean countries. Int J Health Policy Manag. 2014;3:399-407.

31. Ranson K, Law TJ, Bennett S. Establishing health systems financing research priorities in developing countries using a participatory methodology. Soc Sci Med. 2010;70:1933-42.

32. Ali N, Hill C, Kennedy A, IJsselmuiden C. What factors influence national health research agendas in low and middle-income countries. Rec Pap. 2006;5.

33. Kok MO, Rodrigues A, Silva AP, de Haan S. The emergence and current performance of a health research system: lessons from Guinea Bissau. Health Res Policy Syst. 2012;10:5.

34. The Organisation for Economic Co-operation and Development, OECD. The Paris Declaration on Aid Effectiveness and the Accra Agenda for Action. OECD; 2005. http://www.oecd.org/dac/effectiveness/34428351.pdf. 